\title{
Are we making progress?
}

\author{
Han van Krieken
}

Published online: 5 October 2010

(C) Springer-Verlag 2010

This editorial is written a few days before the EAHP/SH meeting in Uppsala, when you read it, the meeting will be over. Although successes of the past do not guarantee success in the future, I am confident that the workshops and symposia will be very good, and that I will learn a lot.

Preparing myself for the meeting brings several thoughts: is it worth the hassle? The days before leaving the laboratory for a week are very busy: I have to finish my cases as much as possible, arrange for handling upcoming results from molecular tests, want to finish all kinds of other issues, want to read the latest literature to be prepared for discussions, prepare the workshop, etc. And I know that after my return, my desk will be full of all kinds of pressing matters. There will soon be an excellent workshop report and the best papers will be published fast too, so why go?

In the first place, it is fun: it is great to meet my colleagues, to hear what they try to find out, the thoughts they have on cases and concepts, and to see Uppsala for the first time and enjoy its culture (including culinary). In the second place, it is good to experience in person the progress of hematopathology. We will discuss difficult cases with many experts, and this cannot be replaced by reading journals, not even the Journal of Hematopathology. And thirdly, and maybe the most important, to be in another environment outside the lab and daily life and to be immersed in hematopathology makes it possible to really think about our profession: something that is important to do regularly.

H. van Krieken $(\square)$

Department of Pathology, Radboud University Nijmegen Medical

Center,

Postbus 9101, 6500 HB Nijmegen, The Netherlands

e-mail: j.vankrieken@pathol.umcn.nl
One thought comes up when reading the recent literature: are we making progress? Of course we know much more than years ago - on proteins, genes, and miRNAs that are important for lymphoma development; we have many more (sub)entities that we can diagnose; and we all use more tools to make a diagnosis in our routine practice. But does it help the patient at all? What good is it to know that there is activated B cell type of diffuse large B cell lymphoma? That there is such a thing as cyclinD1 negative mantle cell lymphoma or EBVassociated diffuse large B cell lymphoma of the elderly? And to be honest, didn't Prof. Lennert recognize all these new things already in a Giemsa stain?

Some epidemiologists report that we are not making progress in cancer treatment, that we are treating earlier precursors or less aggressive forms which only suggests that survival is better, but that the same amount or even more persons die of cancer. Well, this might be true for prostate cancer and breast cancer, but I believe that in lymphomas, real progress can be shown, with mantle cell lymphoma as a prime example. We hematopathologists can be really proud that we were able to recognize this entity and made it possible that it is diagnosed reliably. This has resulted in large multicenter studies, with serious improvement of the survival.

So, yes, I really look forward to a great meeting, which will be enjoyable, and also will give me the feeling that I do something good for my patients; what more can you want!

Han van Krieken 